\title{
Association between IL-1B (-511)/IL-1RN (VNTR) polymorphisms and Type 2 Diabetes: a systematic review and meta-analysis
}

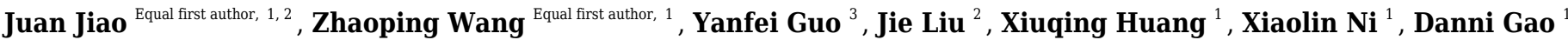

 \\ ${ }^{1}$ The Key Laboratory of Geriatrics, Beijing Institute of Geriatrics, Beijing Hospital, National Center of Gerontology, National Health Commission; Institute of \\ Geriatric Medicine, Chinese Academy of Medical Sciences, Beijing, China \\ 2 Department of Clinical Laboratory, the Seventh Medical Center, Chinese PLA General Hospital, Beijing, China \\ 3 Department of Respiratory and Critical Care Medicine, Beijing Hospital, National Center of Gerontology; Institute of Geriatric Medicine, Chinese Academy \\ of Medical Sciences,, Beijing, China \\ 4 Peking University Fifth School of Clinical Medicine (Beijing Hospital), Beijing, China \\ Corresponding Author: Huiping Yuan \\ Email address: yuanhuiping@126.com
}

Interleukin-1 (IL-1) plays an essential role in the immune pro-inflammatory process, which is regarded as one of many factors in the development of type 2 diabetes mellitus (T2DM). Several case-control studies have illustrated the association of the IL-1B (-511) (rs16944, Chr 2:112,837,290, C/T Intragenic, Transition Substitution) and IL-1RN (VNTR) (gene for IL-1 receptor antagonist, IL-1RA, 86 bp tandem repeats in intron 2) polymorphisms with T2DM risk. However, the results were inconsistent and inconclusive. We performed a metaanalysis (registry number: CRD42021268494) to assess the association of the IL-1B (-511) and IL-1RN (VNTR) polymorphisms with T2DM risk. Random-effects models were applied to calculate the pooled ORs (odds ratios) and 95\% Cls (confidence intervals) to test the strength of the association in the overall group and subgroups stratified by ethnicity, respectively. Between-study heterogeneity and publication bias were evaluated by the $Q$ test, $I^{2}$ statistic, Harbord test, and Peters test accordingly. Sensitivity analyses were also performed. A total of 12 publications evaluating the association of IL-1B (-511) and IL-IRN (VNTR) polymorphisms with the risk of T2DM development were included. The metaanalysis showed that IL-IRN (VNTR) was related to the increasing development of T2DM risk in the recessive model $\left(\mathrm{OR}=1.62,95 \% \mathrm{Cl}: 1.09-2.42, P_{\text {het }}=0.377, P_{z}=0.018\right)$ and in the homozygous model $\left(\mathrm{OR}=2.02,95 \% \mathrm{Cl}\right.$ : $\left.1.07-3.83, P_{\text {het }}=0.085, P_{z}=0.031\right)$, and the IL-IRN 2* allele was found a significant association with evaluated T2DM risk in all ethnicities (OR=2.08, 95\% Cl: 1.43-3.02, $\left.P_{\text {het }} \square 0.001, P_{z} \square 0.001\right)$ and in EA (OR=2.01, 95\% Cl: 1.53-2.66, $\left.P_{\text {het }}=0.541, P_{z} \square 0.001\right)$. Moreover, stratification by ethnicity revealed that $I L-1 B(-511)$ was associated with a decreased risk of T2DM in the dominant model $(\mathrm{OR}=0.76,95 \% \mathrm{Cl}$ : 
0.59-0.97, $\left.P_{\text {het }}=0.218, P_{\mathrm{z}}=0.027\right)$ and codominant model $(\mathrm{OR}=0.73,95 \% \mathrm{Cl}: 0.54-0.99$, $P_{\text {het }}=0.141, P_{z}=0.040$ ) in the East Asian (EA) subgroup. Our results suggest that the IL-IRN $2 *$ allele and $2 * 2 *$ homozygous polymorphism are strongly associated with increasing T2DM risk and that the IL-1B (-511) $T$ allele polymorphism is associated with decreasing T2DM risk in the EA subgroup. 
1 Association between $I L-1 B(-511) / I L-1 R N(V N T R)$ polymorphisms and Type 2



$5{ }^{1}$ The Key Laboratory of Geriatrics, Beijing Institute of Geriatrics, Beijing Hospital, National Center of

6 Gerontology, National Health Commission; Institute of Geriatric Medicine, Chinese Academy of Medical

7 Sciences, P.R. China.

${ }^{2}$ Department of Clinical Laboratory, the Seventh Medical Center, Chinese PLA General Hospital, Beijing, P.R. China.

${ }^{3}$ Department of Respiratory and Critical Care Medicine, Beijing Hospital, National Center of Gerontology; Institute of Geriatric Medicine, Chinese Academy of Medical Sciences, Beijing, P.R. China.

${ }^{4}$ Peking University Fifth School of Clinical Medicine (Beijing Hospital), Beijing, P.R. China.

\#These authors contributed equally to this work.

\section{* Corresponding to:}

Huiping Yuan, MD \& Ph.D

The Key Laboratory of Geriatrics, Beijing Institute of Geriatrics, Beijing Hospital, National Center of Gerontology, National Health Commission;

Institute of Geriatric Medicine, Chinese Academy of Medical Sciences,

P.R. China

NO.1 DaHua Road, Dong Dan, Beijing 100730, P.R. China.

Tel: 0086-10-58115043Ｆax:0086-10-65237929Ｅ-Mail: yuanhuiping@126.com 
29 Abbreviation :

T2DM

type 2 diabetes mellitus

IL-1 Interleukin-1

IL-1 Ra IL-1 receptor antagonist

IL-1 $\quad$ interleukin-1 $\beta$

HWE Hardy-Weinberg Equilibrium

OR odds ratios

CIs confidence intervals

EA East Asian 
Interleukin-1 (IL-1) plays an essential role in the immune pro-inflammatory process, which is regarded as one of many factors in the development of type 2 diabetes mellitus (T2DM). Several case-control studies have illustrated the association of the $I L-1 B$ (-511) (rs16944, Chr 2:112,837,290, C/T Intragenic, Transition Substitution) and $I L-1 R N$ (VNTR) (gene for IL-1 receptor antagonist, IL-1RA, 86 bp tandem repeats in intron 2) polymorphisms with T2DM risk. However, the results were inconsistent and inconclusive. We performed a meta-analysis (registry number: CRD42021268494) to assess the association of the $I L-1 B(-511)$ and $I L-I R N(\mathrm{VNTR})$ polymorphisms with T2DM risk. Random-effects models were applied to calculate the pooled ORs (odds ratios) and 95\% CIs (confidence intervals) to test the strength of the association in the overall group and subgroups stratified by ethnicity, respectively. Between-study heterogeneity and publication bias were evaluated by the $Q$-test, $I^{2}$ statistic, Harbord test, and Peters test accordingly. Sensitivity analyses were also performed. A total of 12 publications evaluating the association of $I L-1 B(-511)$ and $I L-1 R N$ (VNTR) polymorphisms with the risk of T2DM development were included. The meta-analysis showed that $I L-I R N$ (VNTR) was related to the increasing development of T2DM risk in the recessive model $(\mathrm{OR}=1.62,95 \% \mathrm{CI}: 1.09-2.42$, $\left.P_{h e t}=0.377, P_{z}=0.018\right)$ and in the homozygous model $\left(\mathrm{OR}=2.02,95 \% \mathrm{CI}: 1.07-3.83, P_{h e t}=0.085\right.$, $\left.P_{z}=0.031\right)$, and the $I L-1 R N 2 *$ allele was found a significant association with evaluated T2DM risk in all ethnicities $\left(\mathrm{OR}=2.08,95 \% \mathrm{CI}: 1.43-3.02, P_{h e t}<0.001, P_{z}<0.001\right)$ and in EA $\left(\mathrm{OR}=2.01,95 \% \mathrm{CI}: 1.53-2.66, P_{h e t}=0.541, P_{z}<0.001\right)$. Moreover, stratification by ethnicity revealed that $I L-I B(-511)$ was associated with a decreased risk of T2DM in the dominant model $\left(\mathrm{OR}=0.76,95 \% \mathrm{CI}: 0.59-0.97, P_{h e t}=0.218, P_{z}=0.027\right)$ and codominant model $(\mathrm{OR}=0.73,95 \% \mathrm{CI}$ : $0.54-0.99, P_{h e t}=0.141, P_{z}=0.040$ ) in the East Asian (EA) subgroup. Our results suggest that the $I L-1 R N 2 *$ allele and $2 * 2 *$ homozygous polymorphism are strongly associated with increasing 
T2DM risk and that the $I L-1 B(-511) T$ allele polymorphism is associated with decreasing T2DM risk in the EA subgroup.

\section{Introduction:}

The latest data from the $9^{\text {th }}$ edition of the IDF Diabetes Atlas show that approximately 463 million adults (20-79 years) have diabetes, and by 2045, the number will rise to 700 million. Type 2 diabetes mellitus (T2DM) is the most prevalent type of diabetes ( $>90 \%$ of diabetes). The proportion of T2DM patients is increasing in most countries, especially in low- and middleincome countries such as China and India (https://www.idf.org/aboutdiabetes/what-isdiabetes/facts-figures.html). Growing evidence suggests that the risk of T2DM is associated with various factors, such as genetics, ethnicity, environment, and lifestyle. In particular, genetic susceptibility seems to play an essential role in the pathogenesis of T2DM(Hivert et al. 2014). T2DM occurs when $\beta$-cell function progressively deteriorates and fails to compensate for insulin resistance, partly due to the demise of pancreatic $\beta$-cells through apoptosis(Donath \& Halban 2004). The chronic and low-grade inflammation in metabolic organs including the liver, brain, pancreas and adipose tissue is known as metaflammation (metabolism-induced inflammation), which can be widely observed in T2DM(Hotamisligil 2006; Hotamisligil 2017). Increasing evidence has shown that metaflammation plays a vital role in the development of T2DM and its cardiovascular complications(Hotamisligil 2017) and pro-inflammatory cytokines, especially interleukin-1 $\beta$ (IL-1 $\beta$ ), play a key role in this process(Dinarello et al. 2010; Fève \& Bastard 2009; Sathyapalan \& Atkin 2011). Moreover, the increased level of IL-1 $\beta$ in human pancreatic cells due to the elevated glucose concentrations and decreased level of IL-1 receptor antagonist (IL$1 \mathrm{Ra}$ ) in islets of T2DM patients result in impaired insulin secretion, decreased cell proliferation, and apoptosis of $\beta$-cells(Böni-Schnetzler \& Donath 2013). A previous observational study demonstrated that a combined elevation of IL-1 $\beta$ and IL-6 was associated with a roughly threefold increased risk of T2DM, and IL- $1 \beta$ might induce insulin resistance via activating the IкB kinase $\beta$ (Spranger et al. 2003). Furthermore, CANTOS and TRACK trials have evaluated the role of IL-1 inhibition in the treatment of several inflammatory disorders, such as coronary 
105

106

107

108

109

110

111

112

113

114

115

116

117

118

119

120

121

122

123

124

125

126

127

128

129

130

131

artery disease, T2DM and rheumatoid arthritis(Qamar \& Rader 2012; Ruscitti et al. 2019). According to the result from CANTOS trials, canakinumab (a fully humanized monoclonal antibody) could selectively block IL-1 $\beta$, and its efficacy in suppressing both levels of inflammatory markers and clinical symptoms in patients with autoinflammatory disease such as T2DM and impaired glucose tolerance has been observed in this trial(Aday \& Ridker 2018; Rissanen et al. 2012). Therefore, the genetic polymorphisms that regulate the expression levels of IL-1 $\beta$ and IL-1Ra might have an essential impact on the interindividual differences in T2DM. Consisting of 3 linked genes and mapping to chromosome 2q13-24, IL-1 cytokine genes encode IL-1 $\alpha$, IL-1 $\beta$ and IL-1Ra. Both IL- $1 \alpha$ and IL-1 $\beta$ are pro-inflammatory cytokines, while IL-1Ra can inhibit inflammation by competing for receptor binding(Dinarello 2000). In the promoter region, $I L-1 B$ (-511) (rs16944, Chr 2:112,837,290, C/T Intragenic, Transition Substitution) has a bi-allelic polymorphism at position -511, representing the $\mathrm{C} / \mathrm{T}$ transition(Kristiansen et al. 2000). $I L-1 R N(\mathrm{VNTR})$ (gene for IL-1 receptor antagonist, IL-1RA, $86 \mathrm{bp}$ tandem repeats in intron 2) has 5 different alleles: $1 *$ (4 repeats), $2 *$ (2 repeats), $3 *$ (5 repeats), $4 *$ (3 repeats) and $5 *(6$ repeats)(Tarlow et al. 1993). $I L-1 R N 1^{*}$ (4 repeats) and $I L-1 R N 2^{*}$ (2 repeats) are the most common, whereas the others occur much less frequently $(<5 \%)($ Santtila et al. 1998). Many genetic association studies have been performed to estimate the relationship of the $I L-1 B(-511)$ and $I L-1 R N$ (VNTR) polymorphisms with T2DM risk(Achyut et al. 2007; Muktabhant et al. 2013). Several results suggest that there is no relationship between them(Borilova Linhartova et al. 2019; Muktabhant et al. 2013), whereas B.R Achyut et al. showed that both the $I L-1 B(-511)$ and $I L-1 R N$ (VNTR) polymorphisms were associated with susceptibility to T2DM as well as complications, and he indicated that $T 2\left(I L-1 \beta-511 T / I L-1 R N^{*} 2\right)$ haplotype was associated with a roughly twofold increased risk of T2DM(Achyut et al. 2007). Considering the small sample sizes $(\mathrm{n}<600)$ and varying population characteristics (ethnic differences) in different studies, the results are conflicting. To illustrate the potential association of the $I L-1 B(-511)$ and $I L-1 R N$ (VNTR) polymorphisms with T2DM risk, we conducted a meta-analysis including 12 reported publications. 
132

133

134

135

136

137

138

139

140

141

142

143

144

145

146

147

148

149

150

151

152

153

154

155

156

157

\section{Materials and Methods:}

This systematic review was conducted following the Preferred Reporting Items for Systematic Reviews and Meta-Analysis (PRISMA) statement guidelines(Moher et al. 2009). A protocol was registered before commencing this review on PROSPERO (CRD42021268494).

\subsection{The search strategy}

The online databases we searched included PubMed, Web of Science, CNKI (China National Knowledge Infrastructure) and Wanfang. We identified relevant articles reporting the association of $I L-1 R N$ (VNTR) and $I L-1 B(-511)$ polymorphisms with the risk of T2DM in the medical literature through the end of September 12, 2020. This study used a combination of the following search terms: "Type 2 Diabetes Mellitus" or "T2DM" or “interleukin-1" or "IL-1" or "polymorphism" or "genetics" or "association". In addition, we also conducted a hand search to identify relevant data in references from retrieved articles. Juan Jiao and Zhaoping Wang performed the Search Strategy. In case of disagreement, it will be settled by a third assessor's evaluation and discussed until a consistent result was reached.

\subsection{The inclusion and exclusion criteria}

All studies included in this analysis met the following criteria: 1) the study revealed the relationship of $I L-1 B(-511)$ and $I L-1 R N$ (VNTR) with T2DM risk; 2) the design was a "casecontrol study"; 3) the research subjects were humans with T2DM; 4) the publication language was English or Chinese; and 5) the study provided sufficient data to estimate ORs (odds ratios) and 95\% CIs (confidence intervals). The major exclusion criteria were as follows: 1) duplicate data; 2) randomly chosen controls; 3) non-research articles; and 4) insufficient reporting of data.

\subsection{Data extraction}

All data were systematically reviewed and extracted by two investigators (ZPW and DNG) according to a standardized form, and then all of the following information was collected in an electronic database: the first author's name, year of publication, country of origin, ethnicity, total number of cases/controls, genotyping method, diagnostic criteria of T2DM, genotypic 
158 frequencies and language of the report. Disagreement was settled by a third assessor's evaluation 159 and discussed until a consistent conclusion was agreed.

\section{2.4. Assessment of quality score}

161 We assessed the quality score of identified publications based on the Newcastle Ottawa Scale 162 (NOS) (http://www.ohri.ca/programs/clinical_epidemiology/oxford.asp). And the NOS involved 163 "selection", "comparability", and "estimation of outcomes or exposures". The scores ranged 164 from 0 to 9, and the score of "high quality study" was $\geq 6$ (detailed scores see Table S1)(Lo et al. 2014). And the STREGA (Strengthening the REporting of Genetic Association) system was also performed to assessed the methodological quality of all included studies, which includes 22 items with scoring from 0 to 22 (detailed scores see Table S2)(Little et al. 2009). And the score of high quality was 18-22; the score of moderate-high quality was 13-17; the score of low quality was 0-12(Duan et al. 2018).

\subsection{Data analysis}

We conducted this analysis and entered data with Stata software, version 15.0 (Stata Corp., College Station, TX, USA). We used original genotypic distribution data without any adjustment to measure the strength of the association between $I L-1 B(-511) / I L-1 R N$ and T2DM risk by ORs (odds ratios) with 95\% CIs (confidence intervals) under dominant, recessive, additive (overdominant+codominant) and homozygous models. The distributions of genotype frequencies of controls were all consistent with Hardy-Weinberg Equilibrium (HWE) $(P>0.05$, Table 1). Between-study heterogeneity among the studies was tested with Cochran's $Q$ and the $I^{2}$ test statistics. $I^{2}$ was calculated based on the formula $I^{2}=100 \% \times(Q-d f) / Q$. Heterogeneity was regarded as significant when $P_{\text {het }}<0.1$ or $I^{2}>50 \%$. For those with significant heterogeneity, we performed stratified analyses to examine the statistical significance of the difference in ORs according to ethnicity (East Asian, South Asian, North African and Caucasian). We used the random-effects model (DerSimonian and Laird method) which was combined by applying inverse variance-weighted meta-analysis to calculate the pooled OR and 95\% CI, with $P_{z}<0.05$ considered statistically significant(DerSimonian \& Laird 1986). When the heterogeneity was 
185

186

187

188

189

190

191

192

193

194

195

196

197

198

199

200

201

202

203

204

205

206

207

208

209

210

211

significant, sensitivity analyses were conducted to evaluate the influence of each single study by omitting one study at a time and checking the pool effect size for the remainder of the studies. Finally, the Harbord test and Peters test were used when fewer than ten articles were included, as they are more sensitive for assessing publication bias, with $P<0.1$ assuming that the bias was statistically significant.

\section{Results:}

\subsection{Included studies}

Figure 1 shows the detailed process of selecting and assessing eligible studies. We identified 450 publications via the initial keyword search. After screening, 12 publications met our inclusion criteria(Achyut et al. 2007; Blakemore et al. 1996; Borilova Linhartova et al. 2019; Cao et al. 2013; Doody et al. 2017; Lin et al. 2016; Liu et al. 2014; Muktabhant et al. 2013; Tayel et al. 2018; Zhang et al. 2004a; Zhang et al. 2004b; Zhou et al. 2010), and 438 studies were excluded for containing duplicate data, missing critical data, and being review papers or studies that were not related to T2DM. Table 1 illustrates the characteristics of all included publications in this meta-analysis. In terms of polymorphisms and diseases, 6 identified case-control studies, comprising 981 cases and 1225 controls, regarded $I L-1 R N$ (VNTR) to evaluate its association with T2DM risk(Achyut et al. 2007; Blakemore et al. 1996; Borilova Linhartova et al. 2019; Zhang et al. 2004a; Zhang et al. 2004b; Zhou et al. 2010), and 7 identified case-control studies, including 1679 cases and 1442 controls, tested the association between IL-IB (-511) and T2DM risk(Achyut et al. 2007; Cao et al. 2013; Doody et al. 2017; Lin et al. 2016; Liu et al. 2014; Muktabhant et al. 2013; Tayel et al. 2018). Stratified by ethnicity, six publications were performed in East Asian (EA) populations(Cao et al. 2013; Lin et al. 2016; Liu et al. 2014; Zhang et al. 2004a; Zhang et al. 2004b; Zhou et al. 2010), two studies were undertaken in South Asian (SA) populations(Achyut et al. 2007; Doody et al. 2017), two studies were conducted in Caucasian populations(Blakemore et al. 1996; Borilova Linhartova et al. 2019), and the remaining studies were completed in Southeast Asian (SA)(Muktabhant et al. 2013) and North African $\left(\mathrm{NA}_{1}\right)$ populations(Tayel et al. 2018). 
212

213

214

215

216

217

218

219

220

221

222

223

224

225

226

227

228

229

230

231

232

233

234

235

236

237

238

\subsection{Individual polymorphism meta-analysis}

The genotypic distributions of the $I L-1 B(-511)$ and $I L-I R N$ (VNTR) polymorphisms are shown in Table 2. Table 3 shows the meta-analysis results for these two polymorphisms.

For the $I L-1 B$ (-511) polymorphism, seven studies with 1679 cases and 1442 controls were included in the meta-analysis. The results of the pooled analysis suggest that the $I L-1 B(-511)$ polymorphism is not significantly associated with T2DM risk in all study subjects under the dominant model (OR=0.84, 95\% CI: 0.57-1.25, $\left.P_{h e t}=0.001, P_{z}=0.395\right)$ (Table 3 and Figure 2A), recessive model $\left(\mathrm{OR}=0.89,95 \% \mathrm{CI}:\right.$ 0.61-1.31, $\left.P_{\text {het }}<0.001, P_{z}=0.561\right)$ (Table 3), and homozygous model $\left(\mathrm{OR}=0.82,95 \% \mathrm{CI}: 0.48-1.39, P_{\text {het }}<0.001, P_{z}=0.451\right)$ (Table 3$)$. In the stratification analyses by ethnicity, we found that there was a significant association between the $I L-1 B(-511)$ polymorphism and decreasing T2DM risk in the EA population under the dominant model (OR=0.76, 95\% CI: 0.59-0.97, $\left.P_{h e t}=0.218, P_{z}=0.027\right)$ (Table 3 and Figure 2A) and codominant model $\left(\mathrm{OR}=0.73,95 \% \mathrm{CI}: 0.54-0.99, P_{h e t}=0.141, P_{z}=0.040\right)$ (Table 3), but no association was observed under the recessive model $\left(\mathrm{OR}=0.97,95 \% \mathrm{CI}: 0.79-1.20, P_{\text {het }}=0.589\right.$, $\left.P_{z}=0.789\right)$ or homozygous model $\left(\mathrm{OR}=0.80,95 \% \mathrm{CI}: 0.62-1.03, P_{\text {het }}=0.571, P_{z}=0.081\right)$. In other ethnic groups, no association between the $I L-1 B$ (-511) polymorphism and T2DM risk was found. Between-study heterogeneity was found in the dominant, recessive and homozygous models $\left(P_{\text {het }}=0.001, P_{\text {het }}<0.001, P_{\text {het }}<0.001\right)$ (Table 3).

For the $I L-1 R N(\mathrm{VNTR})$ polymorphism, six publications were involved in the meta-analysis (980 cases and 1225 controls). Overall, a significantly increased T2DM risk was found to be associated with $2 *$ allele in all ethnicities $\left(\mathrm{OR}=2.08,95 \% \mathrm{CI}: 1.43-3.02, P_{\text {het }}<0.001, P_{z}<0.001\right)$ and in EA $\left(\mathrm{OR}=2.01,95 \% \mathrm{CI}: 1.53-2.66, P_{h e t}=0.541, P_{z}<0.001\right)$ (Table 3). Pooling data also revealed that this polymorphism is strongly associated with an increasing T2DM risk in the recessive model (OR=1.62, 95\% CI: 1.09-2.42, $\left.P_{h e t}=0.377, P_{z}=0.018\right)$ (Table 3 and Figure 3A) and homozygous model $\left(\mathrm{OR}=2.02,95 \% \mathrm{CI}: 1.07-3.83, P_{\text {het }}=0.085, P_{z}=0.031\right)$ (Table 3 and Figure 3B), but there was no association in the dominant model $(\mathrm{OR}=1.35,95 \% \mathrm{CI}: 0.79-2.31$, $P_{h e t}<0.001, P_{z}=0.275$ ) (Table 3). Between-study heterogeneity was found in the dominant model 
239

240

241

242

243

244

245

246

247

248

249

250

251

252

253

254

255

256

257

258

259

260

261

262

263

264

265

$\left(P_{\text {het }}<0.001\right)$ (Table 3).

\subsection{Sensitivity and publication bias analysis}

We next performed sensitivity analysis on the association between IL-1 $\beta(-511)$ and T2DM. The results showed that Achyut's study had an influence on the pooled OR in the IL-1 $\beta$ (-511)dominant model $(\mathrm{OR}=0.71,95 \% \mathrm{CI}$ : $0.53-0.96)$ and homozygous model $(\mathrm{OR}=0.65,95 \% \mathrm{CI}$ : 0.44-0.97) (Figure 2B, D) but did not affect the pooled OR in the recessive model (Figure 2C). Achyut's study was performed in a SA population; thus, there was no influence on the pooled OR in the EA population. Due to the lack of heterogeneity in IL-1RN recessive and homozygous models, sensitivity analysis was not performed.

The results of the Harbord test and Peters test showed no publication bias for $I L-1 B(-511)$ in the dominant model ( $P_{\text {har }}=0.759$ and $P_{p e t}=0.881$, respectively) (Figure 4A). Moreover, no evidence of publication bias was found for $I L-1 R N$ (VNTR) in the recessive $\left(P_{h a r}=0.498\right.$ and $P_{p e t}=0.495$, respectively) or homozygous models ( $P_{\text {har }}=0.634$ and $P_{p e t}=0.481$, respectively) (Figure 4B, C).

\section{Discussion:}

The $I L-1 B(-511)$ and $I L-I R N$ (VNTR) polymorphisms have been reported to be related to the pathogenesis of T2DM(Ehses et al. 2009; Masters et al. 2010), and many case-control studies have illustrated the association of $I L-1 B(-511)$ and $I L-1 R N$ (VNTR) polymorphisms with T2DM risk. However, each individual study may not have been powerful, causing their results to be controversial. Given the above, we conducted the present meta-analysis to derive a more precise evaluation of the association of $I L-1 B(-511)$ and $I L-1 R N$ (VNTR) polymorphisms with T2DM risk. We found that i) the $T$ allele of $I L-1 B(-511)$ was related with a decreased T2DM risk in the EA subgroup; ii) significantly elevated risk of developing T2DM was observed to be associated with the $2 *$ allele in all ethnicities and EA subgroup, and its carriers of the $I L-1 R N$ (VNTR) polymorphism had an increased risk of developing T2DM among all ethnicities; iii) compared to the $1 * / 1 *$ homozygotes, the $2 * / 2 *$ homozygotes of the $I L-1 R N$ (VNTR) polymorphism had an increased risk of T2DM development; and iv) no significant association was observed between the IL-IRN (VNTR) polymorphism and T2DM risk in the EA subgroup. The results of 
266

267

268

269

270

271

272

273

274

275

276

277

278

279

280

281

282

283

284

285

286

287

288

289

290

291

292

sensitivity analysis showed that Achyut's study affected the pooled ORs in the IL-1 $\beta(-511)$ dominant and homozygous models. However, Achyut's study did not influence the pooled OR in the EA subgroup after stratification by ethnicity. Therefore, the result of the association between $I L-1 B(-511)$ and the decreased risk of T2DM in the dominant model in the EA subgroup was convincing.

First, IL-1 $\beta$ was considered a mediator of fever, and rapidly, it was found that IL-1 $\beta$ induced innate immunity to defend against pathogens. However, chronic overexpression of IL-1 $\beta$ has been related to multiple immune diseases, including T2DM(Mandrup-Poulsen 1996). Eventually, it was suggested that IL-1 $\beta$ can induce the inflammatory microenvironment of islets, leading to impaired insulin secretion, decreased cell proliferation and apoptosis of $\beta$-cells, ultimately contributing to the development of T2DM(Rhodes 2005). Donath, M Y et al. extensively described the development of islet inflammation in GK rats, suggesting that the expression of pro-inflammatory cytokines IL-1 $\beta$ and others (IL-6, TNF $\alpha$ ) was increased in islets, while elevated expression levels of many chemokines (CXCL1/KC, MCP-1, MIP-1 $\alpha$ ) and infiltration of immune cells in islets were observed(Ehses et al. 2009). In all cases, macrophage infiltration is increased in the islet inflammatory process(Ehses et al. 2007). Moreover, two independent studies have now indicated that the numbers of islet-related $\mathrm{CD}^{+} 8^{+}$cells are increased in T2DM patients(Ehses et al. 2007; Richardson et al. 2009). In addition, data obtained from laser-captured $\beta$-cells from T2DM patients have shown that evaluated expression levels of IL-1 $\beta$ and chemokines possibly led to this immune cell infiltration(Böni-Schnetzler et al. 2008). Since it can regulate various inflammatory processes, any change in the level of IL-1 $\beta$ in blood or tissue possibly affects these processes. Larsen et al. suggested that blocking IL-1 $\beta$ is a potential therapy in the treatment of T2DM(Larsen et al. 2007). The $I L-1 B(-511) C$ allele is associated with higher expression of IL-1 $\beta$ and with severe inflammation in the liver, while the (-511) $T$ allele is associated with lower levels of IL-1ß(Hirankarn et al. 2006; Vishnoi et al. 2008). In this metaanalysis, we found that the $I L-1 B(-511) T$ allele had a decreased T2DM risk in the EA subgroup, suggesting an influence of the $I L-1 B(-511)$ polymorphism system in this ethnic group. 
293 The $I L-1 R N 2 *$ allele (two repeats) is associated with increased IL-1Ra levels(Danis et al. 1995),

294 which can compete with an inhibitor of IL-1 $\beta$ by binding to the IL-1 receptor. The $2 *$ allele

295 significantly increases the IL-1 $\beta$ secretion in vitro and balances the expression of IL-1 $\beta$ and IL-

$2961 \mathrm{Ra}($ Santtila et al. 1998), and their ratio (IL-1Ra/IL-1 $\beta$ ) determines the severity of inflammation.

297 It has been shown that the $I L-1 R N 2 *$ allele is associated with a low ratio (IL-1Ra/IL-1 $\beta$ ),

298 thereby inducing a longer and more severe pro-inflammation(Witkin et al. 2002). The frequency

299 of the $2 *$ allele is increased in inflammatory conditions or autoimmune diseases(Tountas et al.

300 1999; van der Paardt et al. 2002). Consistently, this meta-analysis suggested that the $I L-1 R N 2 *$

301 allele and $2 * 2 *$ homozygotes increased T2DM risk, which indicated that the IL-1RN $2 *$ allele

302 and $2 * 2 *$ homozygote polymorphism play critical roles in the development of T2DM.

303 Although we have devoted considerable efforts and resources to testing the potential association of the $I L-I B(-511)$ and $I L-I R N$ (VNTR) polymorphisms with T2DM risk, this analysis still has some limitations. First, significant heterogeneity was found in pooled analyses between the $I L$ $1 B(-511)$ polymorphism and T2DM risk. Due to the limited number of included publications, we conducted further ethnic stratification analysis and meta-regression to identify the exact sources of between-study heterogeneity. The meta-regression results showed that ethnicity was not the source of heterogeneity (both values of $\operatorname{tau}^{2}$ were not much different (0.34 vs 0.40$)$ ). Some possible relevant factors (genotyping method, sex) may lead to heterogeneity. However, subgroup analysis can significantly reduce heterogeneity. Second, the literature articles were primarily published in English or Chinese; thus, some eligible publications may be missing, causing some bias. Third, the publications included have some confounders, such as age, sex, diet, and exercise, whereas we used only the raw data to conduct pooled analysis; therefore, we were unable to control these possible confounders or test the potential gene-environment interactions. Fourth, the number of included publications was limited; thus, additional studies with large sample sizes and a wider variety of ethnicities are needed in the future to evaluate the association.

319 In conclusion, our meta-analysis first indicated that the $I L-1 B(-511) T$ allele polymorphism is 
320 associated with decreased T2DM risk in the EA population and that the $I L-1 R N 2^{*}$ allele and $3212 * 2 *$ homozygote polymorphism are strongly associated with increased T2DM risk. Further 322 well-designed studies including different ethnicities with large sample sizes are needed to verify 323 this conclusion.

324

325

326

327

328

329

330

331

332

333

334

335

336

337

338

339

340

341

342

343

344

345

346

Peer] reviewing PDF | (2021:07:63442:1:2:NEW 9 Sep 2021) 
References:

Achyut BR, Srivastava A, Bhattacharya S, and Mittal B. 2007. Genetic association of interleukin-1beta (-511C/T) and interleukin-1 receptor antagonist (86 bp repeat) polymorphisms with Type 2 diabetes mellitus in North Indians. Clin Chim Acta 377:163-169. 10.1016/j.cca.2006.09.012

Aday AW, and Ridker PM. 2018. Antiinflammatory Therapy in Clinical Care: The CANTOS Trial and Beyond. Front Cardiovasc Med 5:62. 10.3389/fcvm.2018.00062

Blakemore AI, Cox A, Gonzalez AM, Maskil JK, Hughes ME, Wilson RM, Ward JD, and Duff GW. 1996. Interleukin-1 receptor antagonist allele (IL1RN*2) associated with nephropathy in diabetes mellitus. Hum Genet 97:369-374. 10.1007/bf02185776

Böni-Schnetzler M, and Donath MY. 2013. How biologics targeting the IL-1 system are being considered for the treatment of type 2 diabetes. Br J Clin Pharmacol 76:263-268. 10.1111/j.1365-2125.2012.04297.x

Böni-Schnetzler M, Thorne J, Parnaud G, Marselli L, Ehses JA, Kerr-Conte J, Pattou F, Halban PA, Weir GC, and Donath MY. 2008. Increased interleukin (IL)-1beta messenger ribonucleic acid expression in beta -cells of individuals with type 2 diabetes and regulation of IL-1beta in human islets by glucose and autostimulation. J Clin Endocrinol Metab 93:4065-4074. 10.1210/jc.2008-0396

Borilova Linhartova P, Poskerova H, Tomandlova M, Bartova J, Kankova K, Fassmann A, and Izakovicova Holla L. 2019. Interleukin-1 Gene Variability and Plasma Levels in Czech Patients with Chronic Periodontitis and Diabetes Mellitus. Int J Dent 2019:6802349. 10.1155/2019/6802349

Cao Y, Wan Q, Tang XP, Song XQ, Chen Z, and Chen F. 2013. The relationship between interleukin -1 $\beta-511(\mathrm{C} / \mathrm{T})$ gene polymorphism and type 2 diabetes mellitus. IMMUNOLOGICAL JOURNAL 503-506. 1000-8861 (2013) 06-0503-04

Danis VA, Millington M, Hyland VJ, and Grennan D. 1995. Cytokine production by normal human monocytes: inter-subject variation and relationship to an IL-1 receptor antagonist (IL-1Ra) gene polymorphism. Clin Exp Immunol 99:303-310. 10.1111/j.1365-2249.1995.tb05549.x

DerSimonian R, and Laird N. 1986. Meta-analysis in clinical trials. Control Clin Trials 7:177-188. 10.1016/01972456(86)90046-2

Dinarello CA. 2000. The role of the interleukin-1-receptor antagonist in blocking inflammation mediated by interleukin-1. N Engl J Med 343:732-734. 10.1056/nejm200009073431011

Dinarello CA, Donath MY, and Mandrup-Poulsen T. 2010. Role of IL-1 beta in type 2 diabetes. Current Opinion in Endocrinology Diabetes and Obesity 17:314-321. 10.1097/MED.0b013e32833bf6dc

Donath MY, and Halban PA. 2004. Decreased beta-cell mass in diabetes: significance, mechanisms and therapeutic implications. Diabetologia 47:581-589. 10.1007/s00125-004-1336-4

Doody NE, Dowejko MM, Akam EC, Cox NJ, Bhatti JS, Singh P, and Mastana SS. 2017. The Role of TLR4, TNF$\alpha$ and IL-1 $\beta$ in Type 2 Diabetes Mellitus Development within a North Indian Population. Ann Hum Genet 81:141-146. 10.1111/ahg.12197

Duan L, Xue Z, Ji H, Zhang D, and Wang Y. 2018. Effects of CYP2R1 gene variants on vitamin D levels and status: A systematic review and meta-analysis. Gene 678:361-369. 10.1016/j.gene.2018.08.056

Ehses JA, Lacraz G, Giroix MH, Schmidlin F, Coulaud J, Kassis N, Irminger JC, Kergoat M, Portha B, HomoDelarche F, and Donath MY. 2009. IL-1 antagonism reduces hyperglycemia and tissue inflammation in the 
type 2 diabetic GK rat. Proc Natl Acad Sci U S A 106:13998-14003. 10.1073/pnas.0810087106

Ehses JA, Perren A, Eppler E, Ribaux P, Pospisilik JA, Maor-Cahn R, Gueripel X, Ellingsgaard H, Schneider MK, Biollaz G, Fontana A, Reinecke M, Homo-Delarche F, and Donath MY. 2007. Increased number of isletassociated macrophages in type 2 diabetes. Diabetes 56:2356-2370. 10.2337/db06-1650

Fève B, and Bastard JP. 2009. The role of interleukins in insulin resistance and type 2 diabetes mellitus. Nat Rev Endocrinol 5:305-311. 10.1038/nrendo.2009.62

Hirankarn N, Kimkong I, Kummee P, Tangkijvanich P, and Poovorawan Y. 2006. Interleukin-1 beta gene polymorphism associated with hepatocellular carcinoma in hepatitis B virus infection. World Journal of Gastroenterology 12:776-779. 10.3748/wjg.v12.i5.776

Hivert MF, Vassy JL, and Meigs JB. 2014. Susceptibility to type 2 diabetes mellitus--from genes to prevention. Nat Rev Endocrinol 10:198-205. 10.1038/nrendo.2014.11

Hotamisligil GS. 2006. Inflammation and metabolic disorders. Nature 444:860-867. 10.1038/nature05485

Hotamisligil GS. 2017. Inflammation, metaflammation and immunometabolic disorders. Nature 542:177-185. 10.1038/nature21363

Kristiansen OP, Pociot F, Johannesen J, Bergholdt R, Dinarello CA, Nerup J, and Mandrup-Poulsen T. 2000. Linkage disequilibrium testing of four interleukin-1 gene-cluster polymorphisms in Danish multiplex families with insulin-dependent diabetes mellitus. Cytokine 12:171-175. 10.1006/cyto.1999.0546

Larsen CM, Faulenbach M, Vaag A, Vølund A, Ehses JA, Seifert B, Mandrup-Poulsen T, and Donath MY. 2007. Interleukin-1-receptor antagonist in type 2 diabetes mellitus. $N$ Engl J Med 356:1517-1526. 10.1056/NEJMoa065213

Lin NB, Tang XP, Cao Y, and Wan Q. 2016. Association between interleukin-1 $1-511$ (C/T) gene polymorphism and early diabetic kidney disease. Chin J Diabetes:407-411. 10.3969/j.issn.1006-6187.2016.05.005

Little J, Higgins JP, Ioannidis JP, Moher D, Gagnon F, von Elm E, Khoury MJ, Cohen B, Davey-Smith G, Grimshaw J, Scheet P, Gwinn M, Williamson RE, Zou GY, Hutchings K, Johnson CY, Tait V, Wiens M, Golding J, van Duijn C, McLaughlin J, Paterson A, Wells G, Fortier I, Freedman M, Zecevic M, King R, Infante-Rivard C, Stewart A, and Birkett N. 2009. STrengthening the REporting of Genetic Association Studies (STREGA): an extension of the STROBE statement. PLoS Med 6:e22.

10.1371/journal.pmed.1000022

Liu C, Wang YX, Wu ZX, Zhao Y, and Chi XM. 2014. Study on the Correlation Between IL-1 $\beta$ Rs16944 Gene Polymorphism and Type 2 Diabetes Mellitus in Han People of Liaoning Province. J Clin Res 426-428. 10.3969/j.issn.1671-7171.2014.03.004

Lo CK, Mertz D, and Loeb M. 2014. Newcastle-Ottawa Scale: comparing reviewers' to authors' assessments. BMC Med Res Methodol 14:45. 10.1186/1471-2288-14-45

Mandrup-Poulsen T. 1996. The role of interleukin-1 in the pathogenesis of IDDM. Diabetologia 39:1005-1029. $10.1007 / \mathrm{bf00400649}$

Masters SL, Dunne A, Subramanian SL, Hull RL, Tannahill GM, Sharp FA, Becker C, Franchi L, Yoshihara E, Chen Z, Mullooly N, Mielke LA, Harris J, Coll RC, Mills KHG, Mok KH, Newsholme P, Nunez G, Yodoi J, Kahn SE, Lavelle EC, and O'Neill LAJ. 2010. Activation of the NLRP3 inflammasome by islet amyloid polypeptide provides a mechanism for enhanced IL-1 beta in type 2 diabetes. Nature Immunology 11:897U1501. 10.1038/ni.1935

Moher D, Liberati A, Tetzlaff J, and Altman DG. 2009. Preferred reporting items for systematic reviews and meta- 
analyses: the PRISMA statement. PLoS Med 6:e1000097. 10.1371/journal.pmed.1000097

Muktabhant B, Duangjinda M, Sanchaisuriya P, Kananit S, and Schelp FP. 2013. Association of the polymorphism of interleukin-1B $(-511 \mathrm{C} / \mathrm{T})$ with type 2 diabetes mellitus patients with and without family history of a first degree relative with diabetes mellitus. International Journal of Diabetes in Developing Countries 33:236240. 10.1007/s13410-013-0155-x

Qamar A, and Rader DJ. 2012. Effect of interleukin $1 \beta$ inhibition in cardiovascular disease. Curr Opin Lipidol 23:548-553. 10.1097/MOL.0b013e328359b0a6

Rhodes CJ. 2005. Type 2 diabetes-a matter of beta-cell life and death? Science 307:380-384. 10.1126/science. 1104345

Richardson SJ, Willcox A, Bone AJ, Foulis AK, and Morgan NG. 2009. Islet-associated macrophages in type 2 diabetes. Diabetologia 52:1686-1688. 10.1007/s00125-009-1410-z

Rissanen A, Howard CP, Botha J, and Thuren T. 2012. Effect of anti-IL-1 $\beta$ antibody (canakinumab) on insulin secretion rates in impaired glucose tolerance or type 2 diabetes: results of a randomized, placebo-controlled trial. Diabetes Obes Metab 14:1088-1096. 10.1111/j.1463-1326.2012.01637.x

Ruscitti P, Masedu F, Alvaro S, Airò P, Battafarano N, Cantarini L, Cantatore FP, Carlino G, D'Abrosca V, Frassi M, Frediani B, Iacono D, Liakouli V, Maggio R, Mulè R, Pantano I, Prevete I, Sinigaglia L, Valenti M, Viapiana O, Cipriani P, and Giacomelli R. 2019. Anti-interleukin-1 treatment in patients with rheumatoid arthritis and type 2 diabetes (TRACK): A multicentre, open-label, randomised controlled trial. PLoS Med 16:e1002901. 10.1371/journal.pmed.1002901

Santtila S, Savinainen K, and Hurme M. 1998. Presence of the IL-1RA allele 2 (IL1RN*2) is associated with enhanced IL-1beta production in vitro. Scand J Immunol 47:195-198. 10.1046/j.1365-3083.1998.00300.x

Sathyapalan T, and Atkin SL. 2011. Is there a role for immune and anti-inflammatory therapy in type 2 diabetes? Minerva Endocrinologica 36:147-156.

Spranger J, Kroke A, Möhlig M, Hoffmann K, Bergmann MM, Ristow M, Boeing H, and Pfeiffer AF. 2003. Inflammatory cytokines and the risk to develop type 2 diabetes: results of the prospective population-based European Prospective Investigation into Cancer and Nutrition (EPIC)-Potsdam Study. Diabetes 52:812-817. 10.2337/diabetes.52.3.812

Tarlow JK, Blakemore AI, Lennard A, Solari R, Hughes HN, Steinkasserer A, and Duff GW. 1993. Polymorphism in human IL-1 receptor antagonist gene intron 2 is caused by variable numbers of an 86-bp tandem repeat. Hum Genet 91:403-404. 10.1007/bf00217368

Tayel SI, Fouda EAM, Elshayeb EI, Eldakamawy ARA, and El-Kousy SM. 2018. Biochemical and molecular study on interleukin- $1 \beta$ gene expression and relation of single nucleotide polymorphism in promoter region with Type 2 diabetes mellitus. J Cell Biochem 119:5343-5349. 10.1002/jcb.26667

Tountas NA, Casini-Raggi V, Yang H, Di Giovine FS, Vecchi M, Kam L, Melani L, Pizarro TT, Rotter JI, and Cominelli F. 1999. Functional and ethnic association of allele 2 of the interleukin-1 receptor antagonist gene in ulcerative colitis. Gastroenterology 117:806-813. 10.1016/s0016-5085(99)70338-0

van der Paardt M, Crusius JB, García-González MA, Baudoin P, Kostense PJ, Alizadeh BZ, Dijkmans BA, Peña AS, and van der Horst-Bruinsma IE. 2002. Interleukin-1beta and interleukin-1 receptor antagonist gene polymorphisms in ankylosing spondylitis. Rheumatology (Oxford) 41:1419-1423. 10.1093/rheumatology/41.12.1419

Vishnoi M, Pandey SN, Choudhuri G, and Mittal B. 2008. IL-1 gene polymorphisms and genetic susceptibility of 
gallbladder cancer in a north Indian population. Cancer Genet Cytogenet 186:63-68.

470 10.1016/j.cancergencyto.2008.05.004

Witkin SS, Gerber S, and Ledger WJ. 2002. Influence of interleukin-1 receptor antagonist gene polymorphism on disease. Clin Infect Dis 34:204-209. 10.1086/338261

Zhang J, Xiao Q, and Li WN. 2004a. Study of Interleukin-1 Receptor Antagonist Gene Polymorphism in Type 2 Diabetes Mellitus. J Mod Lab Med 15-17.

Zhang PA, Li Y, Xu P, and Wen ZY. 2004b. Study on the Correlation of Interleukin-1 Receptor Antagonist Genotype with NIDDM. J Clin Res 870-873. gene polymorphism and type 2 diabetes. Clin J Med Offic. 10.3969/j.issn.1671-3826.2010.02.028

479 


\section{Figure Legends}

482 Figure 1. Flowchart of study identification process.

483 Figure 2. An overall forest plot of $I L-1 B(-511)$ associated with T2DM risk in the dominant 484 model $(\boldsymbol{T} \boldsymbol{T}+\boldsymbol{T C}$ vs $\boldsymbol{C} \boldsymbol{C})$ and sensitivity analyses.

485 A. Forest plot of $I L-1 B(-511)$ associated with T2DM in the dominant model; (SA: South Asian, 486 SEA: South East Asian, EA: East Asian, NA: North Africa);

487 B. Sensitivity analysis for $T T+T C$ vs $C C$ associated with T2DM in the overall meta-analysis.

488 C. Sensitivity analysis for $T T$ vs $T C+C C$ associated with T2DM in the overall meta-analysis.

489 D. Sensitivity analysis for $T T$ vs $C C$ associated with T2DM in the overall meta-analysis.

490 Figure 3. Forest plot of meta-analysis on $I L-1 R N$ (VNTR) and the risk of T2DM in the 491 recessive model $(2 * 2 *$ vs $2 * 1 *+1 * 1 *)$ and homozygous model $(2 * 2 *$ vs $1 * 1 *)$.

492 A. Forest plot of $I L-1 R N$ (VNTR) associated with T2DM in the recessive model.

493 B. Forest plot of $I L-1 R N$ (VNTR) associated with T2DM in the homozygous model

494 Figure 4. Harbord test for publication bias testing.

495 A. Publication bias of $I L-1 B(-511)$ associated with T2DM in the dominant model (TT + TC vs 496 CC);

497 B. Publication bias of $I L-1 R N$ (VNTR) associated with T2DM in the recessive model $(2 * 2 *$ vs $498 \quad 2 * 1 *+1 * 1 *)$

499 C. Publication bias of $I L-1 R N$ (VNTR) associated with T2DM in the homozygous model $(2 * 2 *$ 500 vs $1 * 1 *)$. 
Figure 1

Flowchart of study identification process.

Figure 1 shows the flowchart of study identification process.

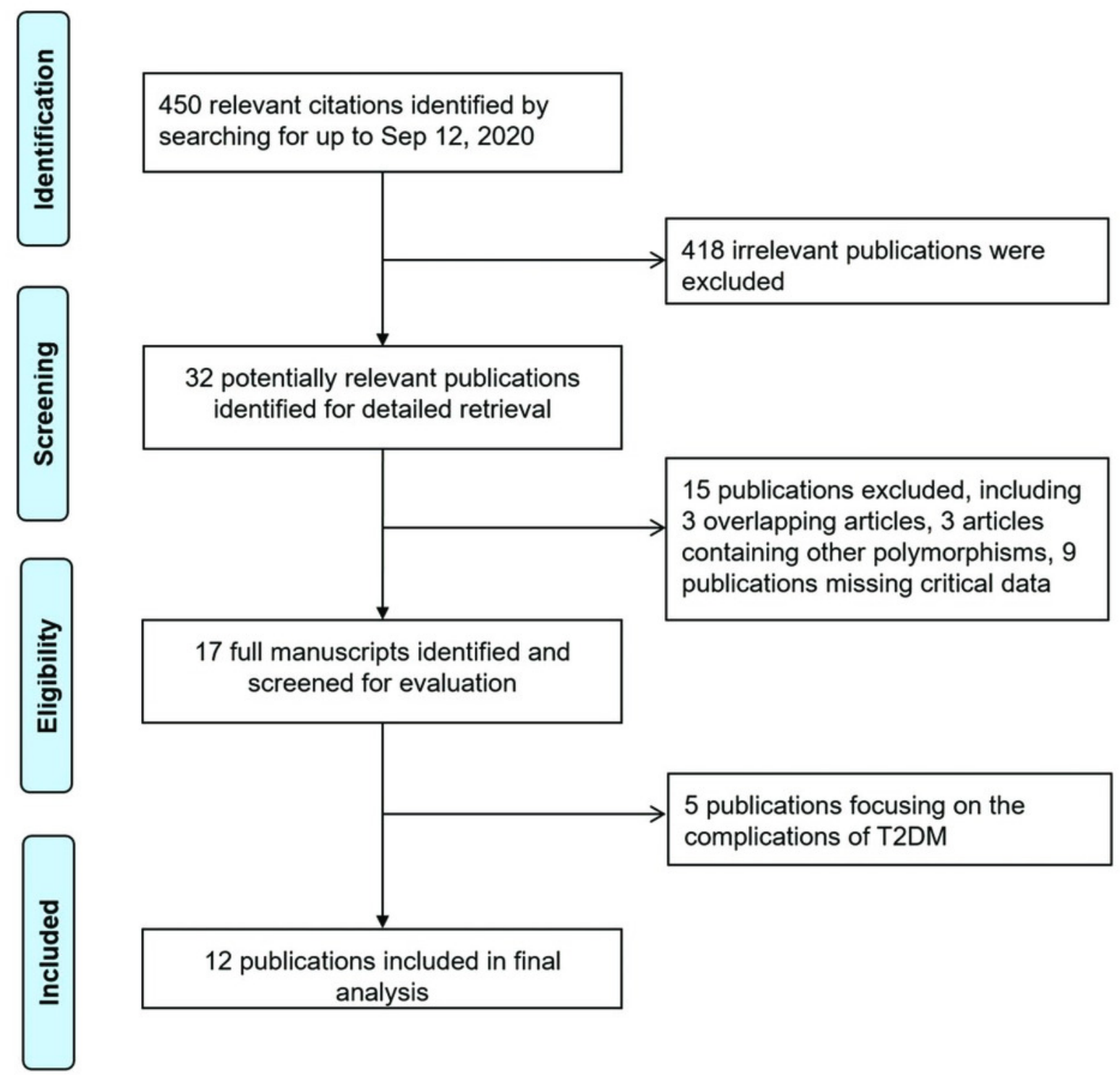


Figure 2

An overall forest plot of IL-1B (-511) associated with T2DM risk in the dominant model $(T+T C$ vs $C C)$ and sensitivity analyses .

'(A) Forest plot of IL-1B (-511) associated with T2DM in the dominant model; (SA: South Asian, SEA: South East Asian, EA: East Asian, NA: North Africa). (B) Sensitivity analysis for $\pi T+T C$ vs $C C$ associated with T2DM in the overall meta-analysis. (C) Sensitivity analysis for $T T$ vs TC $+C C$ associated with T2DM in the overall meta-analysis. (D) Sensitivity analysis for $\Pi T$ vs $C C$ associated with T2DM in the overall meta-analysis.'

A.

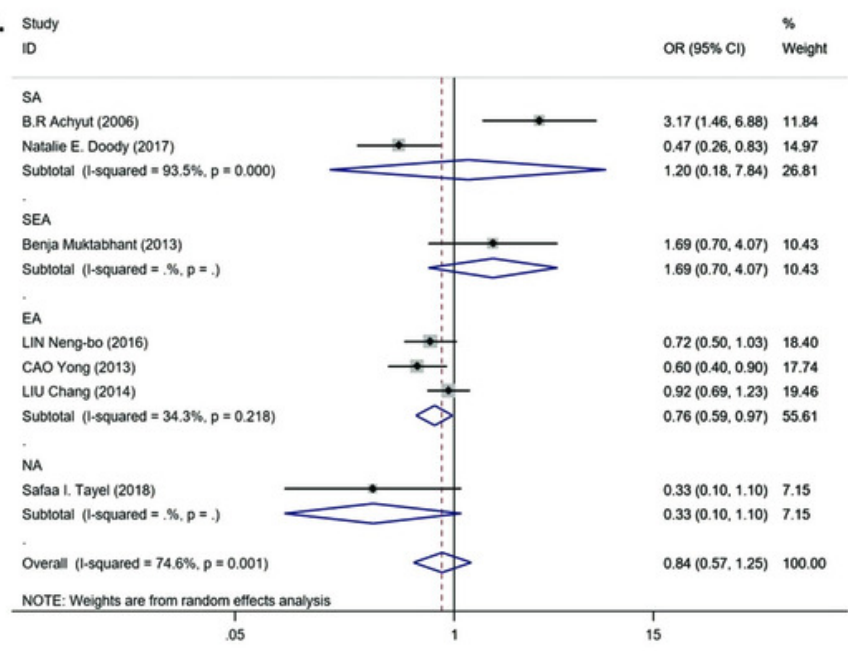

C.

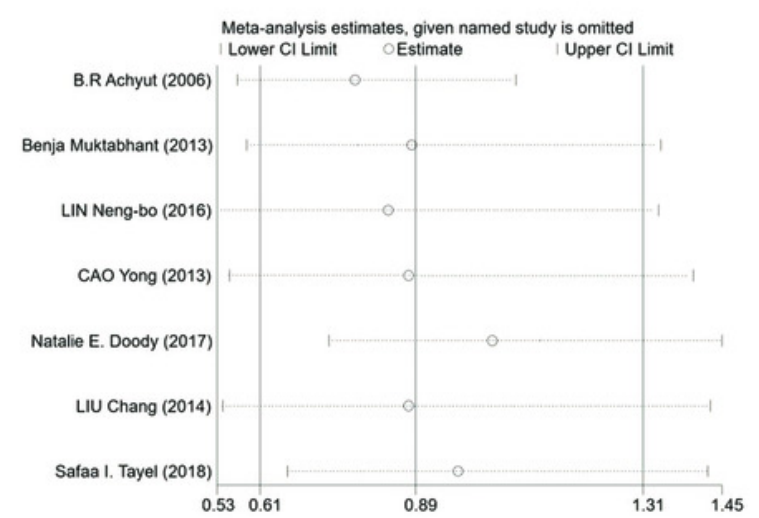

B.



D.

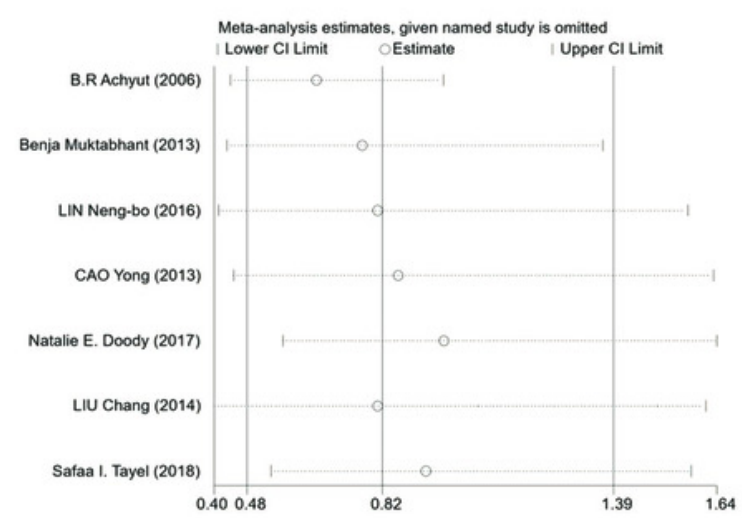


Figure 3

Forest plot of meta-analysis on IL-1RN (VNTR) and the risk of T2DM in the recessive model ( $2 * 2 *$ vs $2 * 1 *+1 * 1 *$ ) and homozygous model ( $2 * 2 *$ vs $1 * 1 *)$.

'(A) Forest plot of IL-1RN (VNTR) associated with T2DM in the recessive model. (B) Forest plot of IL-1RN (VNTR) associated with T2DM in the homozygous model.' 
A. Study

ID
$\%$

OR $(95 \% \mathrm{Cl}) \quad$ Weight
Petra Borilova Linhartova (2019)

B.R Achyut (2006)

ZHANG Ping-an (2004)

ZHANG Jian (2004)

Alexandra I. F. Blakemore (1995)

ZHOU Jian-zhong (2010)

Overall $(\mathrm{I}-$ squared $=6.2 \%, p=0.377)$

NOTE: Weights are from random effects analysis

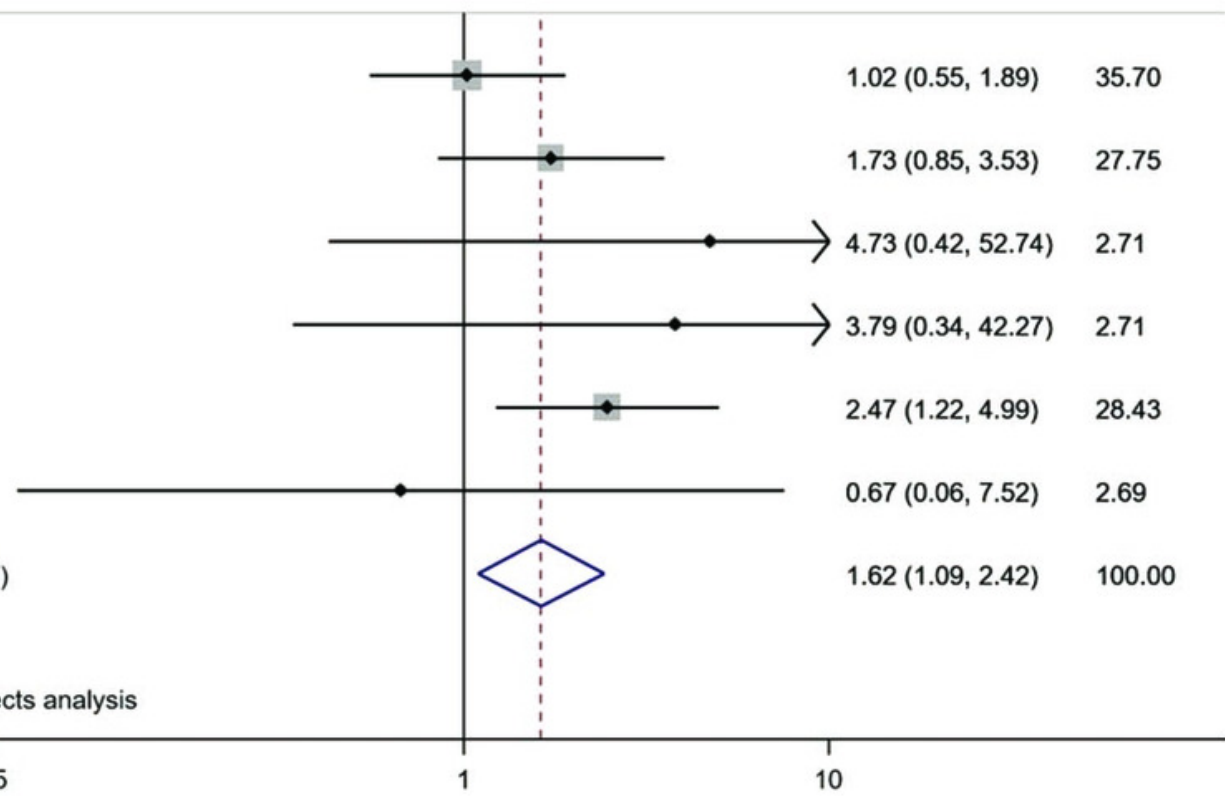

B. Study

ID
$\%$

OR $(95 \% \mathrm{Cl}) \quad$ Weight

Petra Borilova Linhartova (2019)

B.R Achyut (2006)

ZHANG Ping-an (2004)

ZHANG Jian (2004)

Alexandra I. F. Blakemore (1995)

ZHOU Jian-zhong (2010)

Overall $(I-$ squared $=48.3 \%, p=0.085$ )

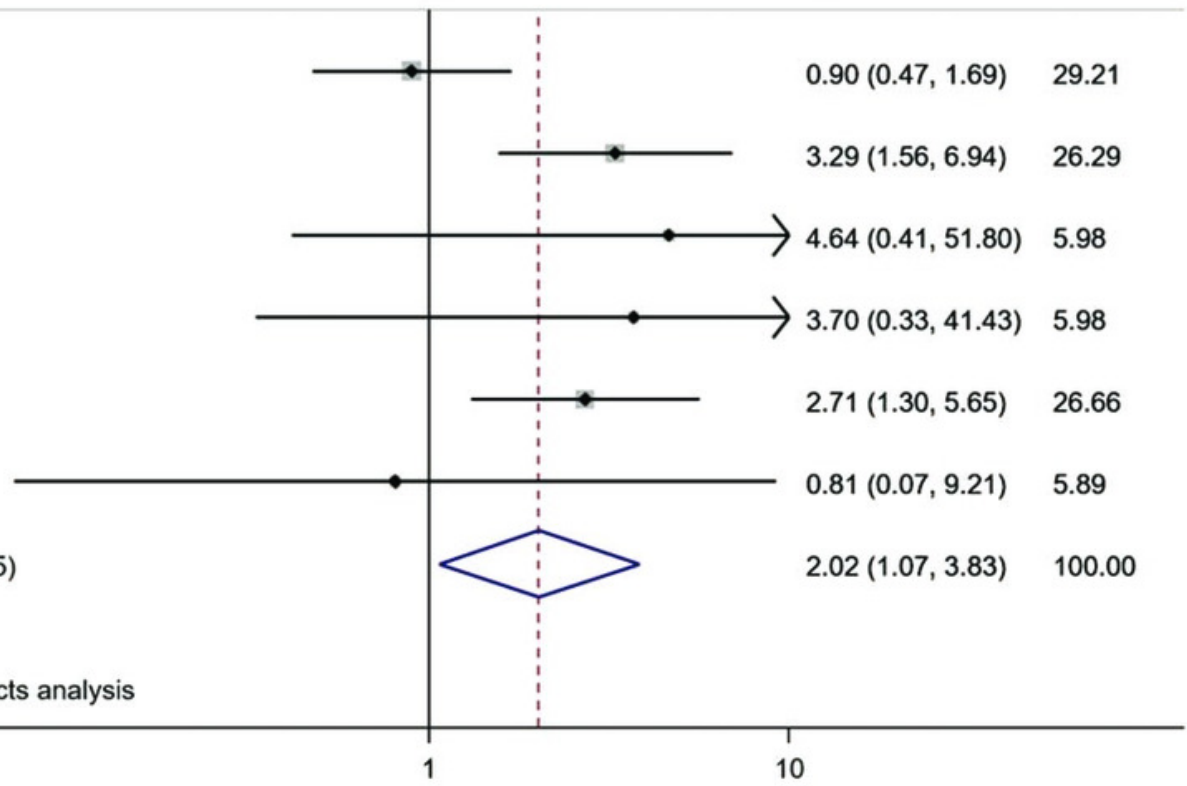


Figure 4

Harbord test for publication bias testing.

'(A) Publication bias of IL-1B (-511) associated with T2DM in the dominant model ( $T T+T C$ vs CC); (B) Publication bias of IL-1RN (VNTR) associated with T2DM in the recessive model ( $2 * 2 *$ vs $2 * 1 *+1 * 1 *$ ); (C) Publication bias of IL-IRN (VNTR) associated with T2DM in the homozygous model ( $2 * 2 *$ vs $1 * 1 *)$.'
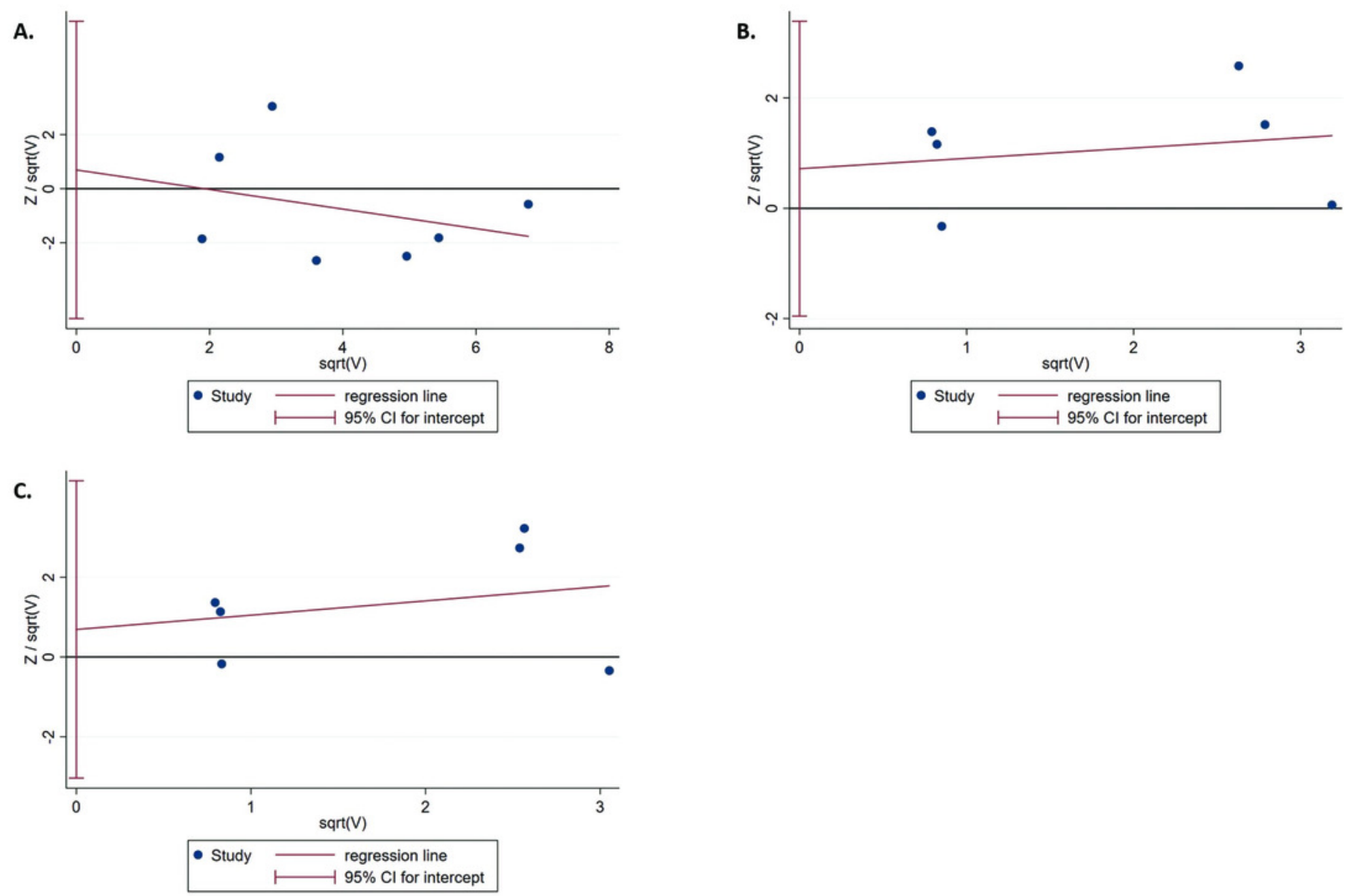


\section{Table $\mathbf{1}$ (on next page)}

Characteristics of Identified Studies on IL-1B (-511)/IL-IRN(VNTR) polymorphism and the risks of T2DM.

Table 1 illustrates the characteristics of all included publications in this meta-analysis. 
1 Table 1. Characteristics of Identified Studies on $I L-1 B(-511) / I L-1 R N(V N T R)$ polymorphism and the risks of T2DM.

\begin{tabular}{|c|c|c|c|c|c|c|c|c|c|c|}
\hline \multirow{2}{*}{ Author } & \multirow{2}{*}{ Year } & \multirow{2}{*}{ Country/Ethnicity } & \multirow{2}{*}{$\begin{array}{l}\text { Diagnostic } \\
\text { Criteria }\end{array}$} & \multirow{2}{*}{$\begin{array}{l}\text { Genotyping } \\
\text { method }\end{array}$} & \multicolumn{2}{|c|}{ Number } & \multirow{2}{*}{ Language } & \multirow{2}{*}{ IL-1 gene } & \multirow{2}{*}{$Q A$} & \multirow{2}{*}{$H W E$} \\
\hline & & & & & Cases & Controls & & & & \\
\hline Zhang Jian & 2004 & China/EA & NA & PCR-RFLP & 106 & 198 & Chinese & $I L-I R N$ & 7 & 1.00 \\
\hline Zhang Ping-an & 2004 & China/EA & WHO, 1999 & PCR-RFLP & 106 & 247 & Chinese & $I L-I R N$ & 8 & 0.70 \\
\hline Zhou Jian-zhong & 2010 & China/EA & WHO, 1999 & PCR-RFLP & 72 & 97 & Chinese & $I L-1 R N$ & 7 & 0.23 \\
\hline $\begin{array}{c}\text { Petra Borilova } \\
\text { Linhartova }\end{array}$ & 2019 & $\begin{array}{c}\text { Czech Republic/ } \\
\text { Caucasian }\end{array}$ & NA & PCR-RFLP & 380 & 212 & English & $I L-1 R N$ & 8 & 1.00 \\
\hline $\begin{array}{c}\text { Alexandra I. F. } \\
\text { Blakemore }\end{array}$ & 1995 & $\begin{array}{c}\text { North of England/ } \\
\text { Caucasian }\end{array}$ & WHO, NA & PCR & 117 & 248 & English & $I L-1 R N$ & 7 & 0.61 \\
\hline B.R Achyut & 2006 & North Indian/SA & WHO, 1999 & PCR-RFLP & 200 & 223 & English & $\begin{array}{c}I L-I R N \\
I L-1 B(-511)\end{array}$ & 8 & $\begin{array}{l}0.10 \\
0.16\end{array}$ \\
\hline Liu Chang & 2014 & China/EA & WHO, 1999 & PCR-RFLP & 583 & 366 & Chinese & $I L-1 B(-511)$ & 7 & 1.00 \\
\hline Cao Yong & 2013 & China/EA & WHO, 1999 & PCR-RFLP & 268 & 263 & Chinese & $I L-1 B(-511)$ & 8 & 0.06 \\
\hline Lin Neng-bo & 2016 & China/EA & WHO, 1999 & PCR-RFLP & 286 & 327 & Chinese & $I L-1 B(-511)$ & 8 & 0.08 \\
\hline $\begin{array}{c}\text { Natalie E. } \\
\text { Doody }\end{array}$ & 2017 & North Indian/SA & WHO, 1999 & PCR-RFLP & 202 & 203 & English & $I L-1 B(-511)$ & 8 & 0.87 \\
\hline $\begin{array}{c}\text { Benja } \\
\text { Muktabhant }\end{array}$ & 2013 & Thailand/SEA & NA & PCR-RFLP & 90 & 30 & English & $I L-1 B(-511)$ & 7 & 0.16 \\
\hline Safaa I. Tayel & 2018 & Egypt/NA 1 & ADA, NA & TaqMan & 50 & 30 & English & $I L-1 B(-511)$ & 8 & 1.00 \\
\hline
\end{tabular}


T2DM=Type 2 diabetes mellitus; EA=East Asian; SA=South Asian; SEA=South East Asian; NA=Not Available (the diagnosis of T2DM was originally based on the presence of clinical symptoms and biochemical); NA1=North African; ADA=American Diabetes Association (fasting blood glucose $\geq 126 \mathrm{mg} / \mathrm{dL}$ or $2 \mathrm{~h}$ blood glucose after overload with $75 \mathrm{~g}$ of glucose $\geq 200 \mathrm{mg} / \mathrm{dL}$ in oral glucose tolerance test (OGTT) or glycated hemoglobin $(\mathrm{HbA1c}) \geq 6.5$ in patients with classic symptoms of hyperglycemia); WHO=World Health Organization (fasting glucose levels [7.0 $\mathrm{mmol} / \mathrm{L}$ or $[126 \mathrm{mg} / \mathrm{dL}$ after a minimum 12-h fast or 2-h post glucose level (oral glucose tolerance test or 2-h OGTT) [11.1 mmol/L or 200 mg/dL] on more than one occasion); QA=Quality Assessment; HWE=Hardy-Weinberg Equilibrium. 


\section{Table 2 (on next page)}

The IL-1 polymorphism distribution in cases and controls.

Table 2 shows the genotypic distributions of the IL-1B (-511) and IL-IRN (VNTR) polymorphisms . 
1 Table 2. The IL-1 polymorphism distribution in cases and controls.

\begin{tabular}{|c|c|c|c|c|c|c|c|c|c|c|}
\hline \multirow{2}{*}{$\begin{array}{l}\text { Gene } \\
\text { IL-1B (-511) }\end{array}$} & \multicolumn{5}{|c|}{ Case } & \multicolumn{5}{|c|}{ Control } \\
\hline & $C$ & $T$ & $C C$ & $T C$ & $T T$ & $C$ & $T$ & $C C$ & $T C$ & $T T$ \\
\hline Cao Yong & 302 & 270 & 78 & 129 & 61 & 332 & 322 & 52 & 147 & 64 \\
\hline Liu Chang & 634 & 532 & 171 & 292 & 120 & 385 & 347 & 101 & 183 & 82 \\
\hline B.R Achyut & 108 & 292 & 9 & 90 & 101 & 175 & 271 & 29 & 117 & 77 \\
\hline Lin Neng-bo & 302 & 270 & 85 & 132 & 69 & 332 & 322 & 76 & 180 & 71 \\
\hline Safaa I. Tayel & 55 & 45 & 16 & 23 & 11 & 21 & 39 & 4 & 13 & 13 \\
\hline Natalie E. Doody & 186 & 218 & 40 & 106 & 56 & 133 & 273 & 21 & 91 & 91 \\
\hline Benja Muktabhant & 90 & 90 & 23 & 44 & 23 & 33 & 27 & 11 & 11 & 8 \\
\hline$I L-1 R N$ & $1^{*}$ & $2 *$ & $1 * / 1 *$ & $1 * / 2 *$ & $2 * / 2 *$ & $1 *$ & $2 *$ & $1 * / 1 *$ & $1 * / 2 *$ & $2 * / 2 *$ \\
\hline B.R Achyut & 227 & 234 & 60 & 107 & 20 & 340 & 92 & 138 & 64 & 14 \\
\hline Zhang Jian & 192 & 34 & 88 & 16 & 2 & 360 & 36 & 163 & 34 & 1 \\
\hline Zhang Ping-an & 192 & 34 & 88 & 16 & 2 & 450 & 44 & 204 & 42 & 1 \\
\hline Zhou Jian-zhong & 107 & 71 & 36 & 35 & 1 & 153 & 41 & 58 & 37 & 2 \\
\hline Alexandra I. F. Blakemore & 154 & 106 & 55 & 44 & 18 & 372 & 124 & 141 & 90 & 17 \\
\hline Petra Borilova Linhartova & 569 & 289 & 220 & 129 & 31 & 303 & 121 & 108 & 87 & 17 \\
\hline
\end{tabular}




\section{Table 3(on next page)}

Meta-analysis of the relationship of the IL-1 polymorphisms with the risks of T2DM.

Table 3 shows the meta-analysis results for these two polymorphisms. 
Table 3. Meta-analysis of the relationship of the IL-1 polymorphisms with the risks of T2DM.

\begin{tabular}{|c|c|c|c|c|c|c|c|c|}
\hline \multirow{2}{*}{ Gene } & \multirow{2}{*}{$\begin{array}{c}\text { No. } \\
\text { studies }\end{array}$} & \multicolumn{3}{|c|}{ Allele comparison } & \multicolumn{4}{|c|}{ Genetic model comparison } \\
\hline & & OR $(95 \% \mathrm{CI})$ & $P_{\text {het }}$ & $P_{z}$ & \multicolumn{2}{|c|}{ OR $(95 \% \mathrm{CI})$} & $P_{\text {het }}$ & $P_{z}$ \\
\hline \multicolumn{9}{|c|}{$I L-1 B(-511)$} \\
\hline \multirow[t]{6}{*}{ Total } & 7 & $0.89(0.68-1.17)$ & $<0.001$ & 0.406 & Dominant & $0.84(0.57-1.25)$ & 0.001 & 0.395 \\
\hline & & & & & Recessive & $0.89(0.61-1.31)$ & $<0.001$ & 0.561 \\
\hline & & & & & Overdominant & $0.92(0.74-1.14)$ & 0.065 & 0.422 \\
\hline & & & & & Codominant & $0.85(0.6-1.21)$ & 0.011 & 0.375 \\
\hline & & & & & Codominant $\#$ & $0.96(0.69-1.34)$ & 0.003 & 0.803 \\
\hline & & & & & Homozygote & $0.82(0.48-1.39)$ & $<0.001$ & 0.451 \\
\hline \multirow[t]{6}{*}{ EA } & 3 & $0.89(0.79-1.01)$ & 0.606 & 0.072 & Dominant & $0.76(0.59-0.97)$ & 0.218 & 0.027 \\
\hline & & & & & Recessive & $0.97(0.79-1.20)$ & 0.589 & 0.789 \\
\hline & & & & & Overdominant & $0.82(0.64-1.04)$ & 0.162 & 0.094 \\
\hline & & & & & Codominant & $0.73(0.54-0.99)$ & 0.141 & 0.040 \\
\hline & & & & & Codominant $^{\#}$ & $1.07(0.86-1.34)$ & 0.385 & 0.531 \\
\hline & & & & & Homozygote & $0.80(0.62-1.03)$ & 0.571 & 0.081 \\
\hline SA & 2 & $1.00(0.33-2.98)$ & $<0.001$ & 0.997 & Dominant & $1.20(0.18-7.84)$ & $<0.001$ & 0.853 \\
\hline SEA & 1 & $1.22(0.68-2.20)$ & - & 0.503 & Dominant & $1.69(0.70-4.07)$ & - & 0.245 \\
\hline NA & 1 & $0.44(0.23-0.85)$ & - & 0.015 & Dominant & $0.33(0.10-1.10)$ & - & 0.070 \\
\hline \multicolumn{9}{|l|}{$I L-1 R N$} \\
\hline \multirow[t]{6}{*}{ Total } & 6 & $2.08(1.43-3.02)$ & $<0.001$ & $<0.001$ & Dominant & $1.35(0.79-2.31)$ & $<0.001$ & 0.275 \\
\hline & & & & & Recessive & $1.62(1.09-2.42)$ & 0.377 & 0.018 \\
\hline & & & & & Overdominant & $1.20(0.72-1.99)$ & $<0.001$ & 0.485 \\
\hline & & & & & Codominant & $1.28(0.73-2.24)$ & $<0.001$ & 0.398 \\
\hline & & & & & Codominant ${ }^{\#}$ & $1.38(0.89-2.13)$ & 0.351 & 0.155 \\
\hline & & & & & Homozygote & $2.02(1.07-3.83)$ & 0.085 & 0.031 \\
\hline \multirow[t]{3}{*}{ EA } & 3 & $2.02(1.53-2.66)$ & 0.541 & $<0.001$ & Dominant & $1.11(0.78-1.59)$ & 0.525 & 0.558 \\
\hline & & & & & Recessive & $2.30(0.57-9.25)$ & 0.470 & 0.243 \\
\hline & & & & & Overdominant & $1.05(0.72-1.54)$ & 0.337 & 0.790 \\
\hline
\end{tabular}




\begin{tabular}{|c|c|c|c|c|c|c|c|c|}
\hline & & & & & Codominant & $1.06(0.74-1.53)$ & 0.371 & 0.749 \\
\hline & & & & & Codominant $^{\#}$ & $2.25(0.53-9.55)$ & 0.356 & 0.270 \\
\hline & & & & & Homozygote & $2.42(0.60-9.78)$ & 0.554 & 0.216 \\
\hline SA & 1 & $3.81(2.84-5.11)$ & - & $<0.001$ & Dominant & $3.75(2.48-5.67)$ & - & $\begin{array}{c}<0.00 \\
1\end{array}$ \\
\hline Caucasian & 2 & $\begin{array}{c}1.60(0.998- \\
2.58)\end{array}$ & 0.02 & 0.051 & Dominant & $1.04(0.54-2.02)$ & 0.017 & 0.901 \\
\hline
\end{tabular}

$\mathrm{CI}=$ confidence interval; IL-1=interleukin- 1 OR $=$ odds ratio; $P_{h e}=P$-value for heterogeneity; $P_{z}=P$-value for overall effect; SA: South Asian, SEA: South East Asian, EA: East Asian, NA: North Africa.

For $I L 1 B$ (-511) polymorphism: dominant ( $T T+T C$ vs $C C)$, recessive ( $T T$ vs $T C+C C)$, overdominant $(C T$ vs $C C+T T)$, codominant $(C T$ vs $C C)$,

6 For $\operatorname{ILIRN}(\mathrm{VNTR})$ polymorphism: dominant $(2 * 2 *+2 * 1 *$ vs $1 * 1 *)$, recessive $(2 * 2 *$ vs $2 * 1 *+1 * 1 *)$, overdominant $(2 * 1 * v s 1 * 1 *+2 * 2 *)$,

7 codominant $(2 * 1 * v s 1 * 1 *)$, codominant $(2 * 1 * v s 2 * 2 *)$ and homozygote $(2 * 2 *$ vs $1 * 1 *)$. 